\title{
EXPERIMENTAL INVESTIGATION ON REFLECTION AND ENERGY LOSS OF TSUNAMI OVER THE PERMEABLE BEACH
}

\author{
Nuray GEDİK ${ }^{1, *}$, Sedat KABDAȘLI ${ }^{2}$, Emel İRTEM $^{1}$ \\ ${ }^{1}$ Department of Civil Engineering, Balıkesir University, Balıkesir, Turkey \\ ${ }^{2}$ Civil Engineering Faculty, İstanbul Technical University, Maslak, İstanbul, Turkey
}

\begin{abstract}
The aim of this study is to investigate the reflection coefficient and the energy loss of tsunami as experimentally. The beach was built as a natural sandy one with grain diameter of $0.35 \mathrm{~mm}$ and the specific gravity of 2.63 . The slopes of the beach were selected as 1/1.5, 1/5 and 1/8, respectively. As a result of experimental investigations, beach slope, tsunami run-up height, incident and reflecting wave heights, the characteristics of the beach material, and specific gravity of the water were determined as the parameters having the effect on both the reflection coefficient of tsunami and wave energy loss. These parameters are obtained as a dimensionless group via Buckingham's Pi theorem. In addition, considering regression analysis, the relationship giving as dimensionless wave energy loss was proposed. The additional experiments were performed for different slopes that are $1 / 2.5,1 / 3.5$ and $1 / 6.5$, respectively in order to verify the proposed equations derived from the study. Furthermore, the total energy values of the incident and the reflecting waves were calculated from the equation given in Coastal Engineering Manuel (CEM). These results were compared with the results of the proposed equations, and it was shown that there was a good agreement between the results.
\end{abstract}

Key words: Tsunami, Reflecting wave height, Incident wave height, Reflection coefficient, Wave energy loss

\section{INTRODUCTION}

A tsunami can be generated by a seaquake, landslide, volcanic eruption, or similar phenomena causing a large displacement of water. It can be modeled as solitary waves [1-14] or N-waves [15,16].

Despite the numeric and experimental studies existed in the literature about tsunami propagation, runup, and run-down, the studies referring tsunami reflections and energy loss are rather limited. Some of the studies performed on both tsunami reflection and energy are summarized below:

Cooker et al. [17] have considered the reflection at a vertical wall of a solitary wave, using a boundary-integral numerical model and the images from a previous study have carried out by Maxworthy (1976). Silva et al. [10] have presented a linear solution for the interaction of tsunamis with coastal defense structures. An emerged porous breakwater and a submerged permeable or impermeable breakwater of arbitrary geometry were studied and the reflection and transmission coefficients were calculated using the inverse Fourier transform. Chen et al. [18] have conducted experiments to investigate propagation and reflection of internal solitary wave in a two-layer fluid. Chang and Liou [19] have used a matching method and a shape transfer to study the reflection and transmission of long waves from trapezoidal breakwaters. A systematic shape transfer is derived to determine wave reflection and transmission.

Other researches have investigated the changes in the tsunami wave energy. For example, Kajiura [20], Dotsenko and Korobkova [21] and Velichko et al. [22] have investigated the energy exchange between the solid bottom and overlying water. 
Li and Raichlen [23] have developed a numerical model to simulate the process of wave breaking and run-up. The energy dissipation of wave breaking was represented by a propagating bore, and the maximum wave run-up on a smooth slope was calculated numerically.

Okal [24] have provided the relations for the energy of tsunamis generated by earthquake and landslides. Okal and Synolakis [25] have investigated tsunami energy generated by seismic dislocations and underwater slumps.

Dutykh and Dias [26] have performed the theoretical studies about tsunami waves originated from bottom motion using incompressible Euler equations and the dispersive and non-dispersive shallow water wave equations. They have reported that only dispersive effects are present in the energy budget and explained the exchange between potential and kinetic energies by solving a Cauchy - Poisson problem of tsunami generation using linear water wave equations.

A tsunami causes large scale losses of life and the property when it reaches to the shallow waters from deep waters. Tsunami protection studies have investigated hard structures like tsunami breakwaters, seawalls etc. and the natural barriers including coastal forest etc. After the 2004 Indian Ocean Tsunami on 26 December 2004, the studies have examined on the effects of tsunami on coastal forests [27-34].

In this paper, we provide results from an experimental study for reflection coefficient and wave energy loss of tsunamis. The beach slope, tsunami run-up height, incident and reflecting wave heights, beach material characteristics, and specific gravity of water were determined as variables affecting the reflection coefficient and energy loss of tsunamis. Effect of these variables is considered as dimensionless parameters and the regression analysis is utilized to establish as those of relationships for wave energy loss.

\section{METHODS}

Solitary wave shape and wave celerity are presented using the first order solitary wave theory as follows [23]:

$$
\begin{gathered}
\eta=\operatorname{Hsech}^{2} \sqrt{\frac{3}{4} \frac{H}{d^{3}}}\left(x-X_{1}\right) \\
c=\sqrt{g(d+H)}
\end{gathered}
$$

where $\mathrm{H}$ is wave height, $\mathrm{d}$ is water depth, $\mathrm{g}$ is acceleration of gravity, $\mathrm{c}$ is wave celerity.

In Grilli et al. [35], dimensionless slope parameter for solitary waves (breaking criteria) is defined as:

$$
S_{o}=1.521 \times \frac{s}{\sqrt{H / d}}
$$

where $\mathrm{s}$ is beach slope and $(\mathrm{H} / \mathrm{d})$ is dimensionless wave height. Waves do not break when $\mathrm{S}_{\mathrm{o}}>0.37$. These results are supported by both computations and experiments. In all experiments in this study, it is observed that $S_{o}$ is greater than 0.37 and waves do not break.

Kinetic energy and potential energy of a solitary wave with wave height $\mathrm{H}$ are obtained as [9] : 


$$
\begin{gathered}
E_{k}=\frac{4 \rho g}{3 \sqrt{3}} H^{3 / 2} d^{3 / 2}+\frac{4 \rho g}{15 \sqrt{3}} H^{5 / 2} d^{1 / 2} \\
E_{p}=\frac{4 \rho g}{3 \sqrt{3}} H^{3 / 2} d^{3 / 2}
\end{gathered}
$$

where $\rho$ is density of water. It can be found that the kinetic energy is almost equal to the potential energy if the incident wave height is not too large. For the kinetic and potential energies, Eq. (6) is used:

$$
E_{k} \approx E_{p}=\frac{4 \rho g}{3 \sqrt{3}} H^{3 / 2} d^{3 / 2}
$$

Total energy in solitary wave is about evenly divided between kinetic and potential energy. Total wave energy per unit crest width is given in below [36]:

$$
E=\frac{8}{3 \sqrt{3}} \rho g H^{3 / 2} d^{3 / 2}
$$

When the wave reaches the maximum run-up position for the non-breaking wave, the potential energy reaches the maximum and kinetic energy goes zero. Then, during the run-down process, the potential energy begins to transform to kinetic energy with the kinetic energy being equal to the potential energy. During this process, the total energy is constant where the energy is conserved [9].

\section{EXPERIMENTS}

\subsection{Experimental Setup}

The experiments were carried out in a glass-walled wave channel of $22.5 \mathrm{~m}$ length, $1.00 \mathrm{~m}$ width, and $0.50 \mathrm{~m}$ depth at the Hydraulics Laboratory, Faculty of Civil Engineering, İstanbul Technical University, İstanbul, Turkey (Figure 1). The permeable beach was built as a natural sandy beach with grain diameter of $0.35 \mathrm{~mm}$ and specific gravity of $2.63 \mathrm{t} / \mathrm{m}^{3}$. In a study conducted by Grilli et al. [35], $1 / 1.73$ and 1/4 slopes are defined as steep slopes, while 1/8 and 1/15 slopes can be evaluated as mild slopes. For this reason, the coastal slopes were selected as $1 / 1.5,1 / 5$ and $1 / 8$ so as to investigate reflection and energy loss realized in the shorelines having steep and mild slope $R u$ is the wave run-up height, $d$ is the water depth, $H$ is the wave height, and $\beta$ is the inclination angle of the plane beach (Figure 1). The tsunami generation mechanism consists of a piston, a PHS16B bearing and a horizontal plate $(0.97 \times 2.00 \times 0.002 \mathrm{~m})$. The piston was a pneumatic cylinder, driven by a manually controlled system. As the piston moves vertically, the plate lifts off and displaces the adjacent fluid, thereby generating long waves $[37,38]$.

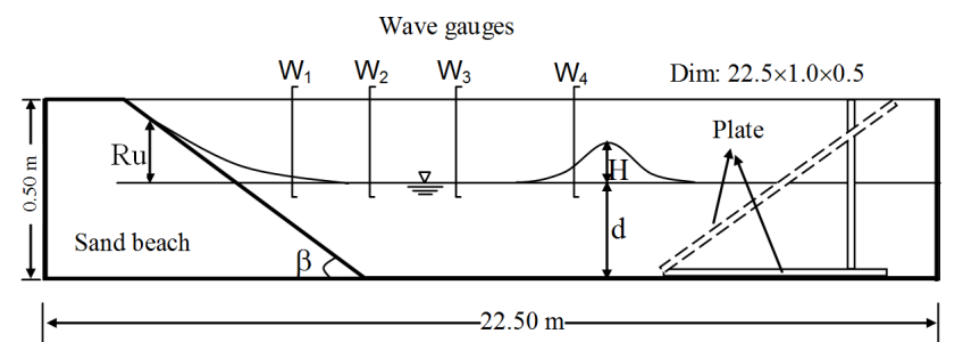

Figure 1. Experimental set-up 
The water surface elevations were measured by four resistance type wave gauges. The wave gauge $\mathrm{W}_{1}$ was installed on the sloping beach and the other wave gauges were installed between the toe of the beach slope and the centre of the wave channel. The run-up height of tsunami was measured both manually and using a video camera. Besides, the suggested relationship is verified by data for $1 / 2.5$, $1 / 3.5$ and $1 / 6.5$ of beach slopes.

\subsection{Experimental Results}

The dependent variables for tsunami energy loss are determined from experimental evaluations. These variables are incident wave height $\left(\mathrm{H}_{\mathrm{i}}\right)$, reflecting wave height $\left(\mathrm{H}_{\mathrm{r}}\right)$, water depth in the constant depth region (d), run-up height $(\mathrm{Ru})$, water density $\left(\gamma_{\mathrm{w}}\right)$, sand density $\left(\gamma_{\mathrm{s}}\right)$, sand diameter $(\mathrm{D})$, the angle of the slope $(\beta)$, the acceleration of gravity $(\mathrm{g})$, total energy of incident wave $\left(\mathrm{E}_{\mathrm{i}}\right)$, and total energy of reflecting wave $\left(\mathrm{E}_{\mathrm{r}}\right)$. This expression can be written as a functional form:

$$
f\left(\mathrm{H}_{\mathrm{i}}, \mathrm{H}_{\mathrm{r}}, \mathrm{d}, \mathrm{Ru}, \gamma_{\mathrm{w}}, \gamma_{\mathrm{s}}, \mathrm{D}, \beta, \mathrm{g}, \mathrm{E}_{\mathrm{i}}, \mathrm{E}_{\mathrm{r}}\right)=0
$$

Choosing the variables $\mathrm{d}, \gamma_{\mathrm{s}}$ and $\mathrm{g}$ as the independent physical variables, the following dimensionless parameters are obtained via $\pi$ theory:

$$
f\left(\frac{\mathrm{H}_{\mathrm{i}}}{\mathrm{d}}, \frac{\mathrm{H}_{\mathrm{r}}}{\mathrm{d}}, \frac{\mathrm{Ru}}{\mathrm{d}}, \frac{\gamma_{\mathrm{s}}}{\gamma_{\mathrm{w}}}, \frac{\mathrm{D}}{\mathrm{d}}, \cot \beta, \frac{\mathrm{E}_{\mathrm{i}}}{\gamma_{\mathrm{w}} \mathrm{d}^{3}}, \frac{\mathrm{E}_{\mathrm{r}}}{\gamma_{\mathrm{w}} \mathrm{d}^{3}}\right)=0
$$

where $\mathrm{H}_{\mathrm{i}} / \mathrm{d}$ is dimensionless incident wave height, $\mathrm{H}_{\mathrm{r}} / \mathrm{d}$ is dimensionless reflecting wave height, $\mathrm{Ru} / \mathrm{d}$ is dimensionless run-up height, $\mathrm{G}_{\mathrm{sb}}=\gamma_{\mathrm{s}} / \gamma_{\mathrm{w}}$ is specific gravity of sand, $\mathrm{D} / \mathrm{d}$ is dimensionless diameter of sand, $\cot \beta$ is dimensionless slope angle, $\mathrm{E}_{\mathrm{i}} / \gamma_{\mathrm{w}} \mathrm{d}^{3}$ is dimensionless total energy of incident wave, and $\mathrm{E}_{\mathrm{r}}$ $/ \gamma_{\mathrm{w}} \mathrm{d}^{3}$ is dimensionless total energy of reflecting wave, $\Delta \mathrm{E} / \gamma_{\mathrm{w}} \mathrm{d}^{3}$ is the dimensionless wave energy loss.

\subsection{Evaluation of Parameters Affected on Reflection}

The slope, incident and reflecting wave heights, run-up height are all the parameters that affect the reflection. The ratio of the reflecting wave height to the incident wave height gives the reflection coefficients (r). For each slope, the exchange of the dimensionless run-up height with reflection coefficient is shown in Figure 2. As can be seen from the figure, since the slope decrease, reflection coefficients decrease. The variation range of reflection coefficients are $0.32-0.6$ for $1 / 8,0.35-0.85$ for $1 / 5$ and $0.58-0.98$ of $1 / 1.5$. The reflection coefficients corresponding to different $\mathrm{Ru} / \mathrm{d}$ for each slope are given in Table 1.

Table 1. The determined reflection coefficient regarding $\mathrm{Ru} / \mathrm{d}$ ratios

\begin{tabular}{lllllllll}
\hline $\mathrm{Ru} / \mathrm{d}$ & Slope & $\mathrm{r}$ & $\mathrm{Ru} / \mathrm{d}$ & Slope & $\mathrm{r}$ & $\mathrm{Ru} / \mathrm{d}$ & Slope & $\mathrm{r}$ \\
\hline \multirow{2}{*}{0.46} & $1 / 1.5$ & 0.895 & & $1 / 1.5$ & 0.866 & & $1 / 1.5$ & 0.837 \\
& $1 / 5$ & 0.851 & 0.51 & $1 / 5$ & 0.799 & 0.56 & $1 / 5$ & 0.746 \\
& $1 / 8$ & & & $1 / 8$ & 0.926 & & $1 / 8$ & \\
\hline \multirow{2}{*}{0.47} & $1 / 1.5$ & 0.889 & & $1 / 1.5$ & 0.860 & & $1 / 1.5$ & 0.831 \\
& $1 / 5$ & 0.841 & 0.52 & $1 / 5$ & 0.788 & 0.57 & $1 / 5$ & 0.735 \\
& $1 / 8$ & 0.167 & & $1 / 8$ & & & $1 / 8$ & \\
\hline \multirow{2}{*}{0.48} & $1 / 1.5$ & 0.883 & & $1 / 1.5$ & 0.854 & & $1 / 1.5$ & 0.826 \\
& $1 / 5$ & 0.830 & 0.53 & $1 / 5$ & 0.777 & 0.58 & $1 / 5$ & 0.725 \\
& $1 / 8$ & 0.357 & & $1 / 8$ & & & $1 / 8$ & \\
\hline \multirow{2}{*}{0.49} & $1 / 1.5$ & 0.877 & & $1 / 1.5$ & 0.849 & & $1 / 1.5$ & 0.820 \\
& $1 / 5$ & 0.820 & 0.54 & $1 / 5$ & 0.767 & 0.59 & $1 / 5$ & 0.714 \\
& $1 / 8$ & 0.546 & & $1 / 8$ & & & $1 / 8$ & \\
\hline \multirow{2}{*}{0.50} & $1 / 1.5$ & 0.872 & & $1 / 1.5$ & 0.843 & & $1 / 1.5$ & 0.814 \\
& $1 / 5$ & 0.809 & 0.55 & $1 / 5$ & 0.756 & 0.60 & $1 / 5$ & 0.704 \\
\hline
\end{tabular}


The dimensionless run-up height varied from 0.47 to 0.51 values for $1 / 8$ slope that were shown in Figure 2. Therefore, it can be not given reflection coefficients for $\mathrm{Ru} / \mathrm{d}>0.51$ stated in Table 1 . As can be seen from Figure 2 and Table 1, as the slope increases, the reflection coefficient increases. Moreover, it can be seen that the reflection coefficient decreases as Ru/d increases at the same slope. Figure 3 has been established to be able to evaluate the effect of the incident wave height on reflection coefficient according to slopes. It can be observed from Figure 3 and Table 2 that as the incident wave height increases, the reflection coefficient decreases. As $\mathrm{H}_{\mathrm{i}} / \mathrm{d}$ varies from 0.2 to 0.3 values for $1 / 8$ slope, the reflection coefficients are not given for $\mathrm{H}_{\mathrm{i}} / \mathrm{d}>0.3$ in Table 2.

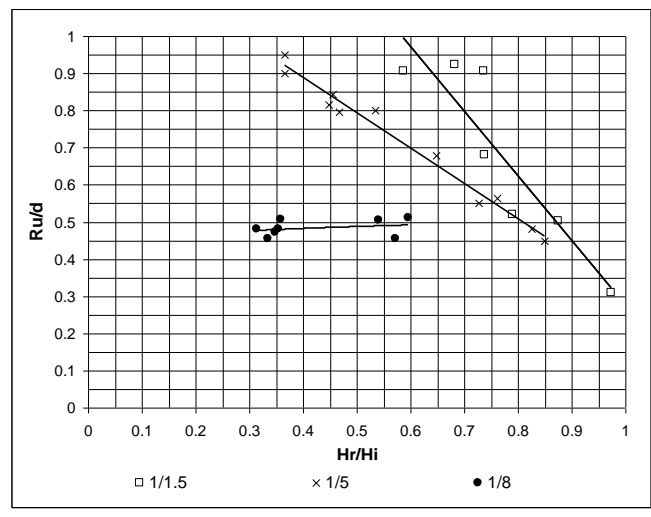

Figure 2. Variation of reflection coefficient with Ru/d for different slopes

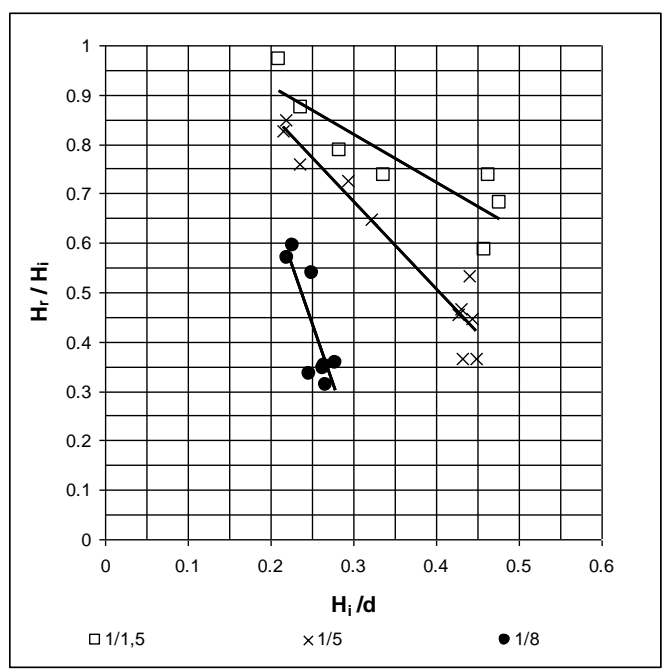

Figure 3. Variation of reflection coefficient with incident wave height 
Table 2. The determined reflection coefficient regarding $\mathrm{H}_{\mathrm{i}} / \mathrm{d}$ ratios

\begin{tabular}{lllllllll}
\hline $\mathrm{H}_{\mathrm{i}} / \mathrm{d}$ & Slope & $\mathrm{r}$ & $\mathrm{H}_{\mathrm{i}} / \mathrm{d}$ & Slope & $\mathrm{r}$ & $\mathrm{H}_{\mathrm{i}} / \mathrm{d}$ & Slope & $\mathrm{r}$ \\
\hline \multirow{3}{*}{0.2} & $1 / 1.5$ & 0.917 & & $1 / 1.5$ & 0.819 & & $1 / 1.5$ & 0.741 \\
& $1 / 5$ & 0.860 & 0.3 & $1 / 5$ & 0.683 & 0.4 & $1 / 5$ & 0.542 \\
& $1 / 8$ & 0.678 & & $1 / 8$ & 0.198 & & $1 / 8$ & - \\
\hline \multirow{3}{*}{0.22} & $1 / 1.5$ & 0.897 & & $1 / 1.5$ & 0.800 & & $1 / 1.5$ & 0.721 \\
& $1 / 5$ & 0.825 & 0.32 & $1 / 5$ & 0.648 & 0.42 & $1 / 5$ & 0.506 \\
& $1 / 8$ & 0.582 & & $1 / 8$ & 0.102 & & $1 / 8$ & - \\
\hline \multirow{3}{*}{0.24} & $1 / 1.5$ & 0.878 & & $1 / 1.5$ & 0.780 & & $1 / 1.5$ & 0.702 \\
& $1 / 5$ & 0.789 & 0.34 & $1 / 5$ & 0.612 & 0.44 & $1 / 5$ & 0.471 \\
& $1 / 8$ & 0.486 & & $1 / 8$ & 0.006 & & $1 / 8$ & -0.378 \\
\hline \multirow{3}{*}{0.26} & $1 / 1.5$ & 0.858 & & $1 / 1.5$ & 0.780 & & $1 / 1.5$ & 0.682 \\
& $1 / 5$ & 0.754 & 0.36 & $1 / 5$ & 0.612 & 0.46 & $1 / 5$ & 0.436 \\
& $1 / 8$ & 0.390 & & $1 / 8$ & 0.006 & & $1 / 8$ & - \\
\hline \multirow{3}{*}{0.28} & $1 / 1.5$ & 0.839 & & $1 / 1.5$ & 0.760 & & $1 / 1.5$ & 0.663 \\
& $1 / 5$ & 0.719 & 0.38 & $1 / 5$ & 0.577 & 0.48 & $1 / 5$ & 0.400 \\
& $1 / 8$ & 0.294 & & $1 / 8$ & - & & $1 / 8$ & - \\
\hline
\end{tabular}

\subsection{Evaluation of Parameters Affected on Tsunami Energy Loss}

The total energy of the incident and reflecting waves were calculated by using Eq. (7). The difference between the total energy of incident and reflecting waves gives the energy consumed during the runup and run-down of the waves due to incline and friction and as such can be defined as the energy loss. Variation of the dimensionless wave energy loss $\left(\Delta \mathrm{E} / \gamma \mathrm{wd}^{3}\right)$, with the reflection coefficient, slope, incident and reflecting wave height, and run-up height were all shown in Figure 4(a-d). As can be seen from these figures, the dimensionless wave energy loss is occurred in direct proportion to the slope, the incident wave height and run-up height while in inverse proportion to the reflection coefficient. In spite of the increase in the coefficient of reflection observed at 1/8 slope, the dimensionless run-up height remained at nearly the same values, which are emphasized in Figure 2, have caused the distribution between the dimensionless wave energy loss associated with this slope and the dimensionless run-up height to be different from those of other slopes (Figure 4-d).

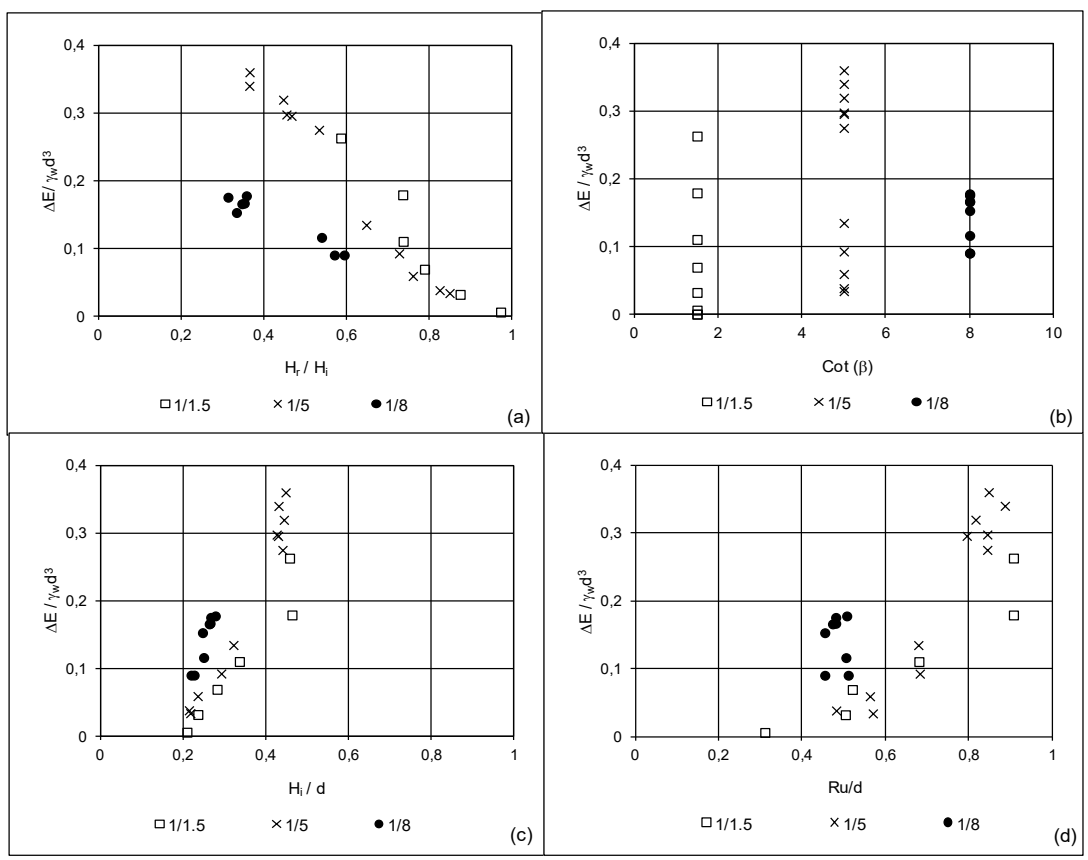

Figure 4. Variation of $\left(\Delta \mathrm{E} / \gamma_{\mathrm{w}} \mathrm{d}^{3}\right)$ with (a) reflection coefficients, (b) different slope, (c) $\mathrm{H}_{\mathrm{i}} / \mathrm{d}$, and (d) $\mathrm{Ru} / \mathrm{d}$ 


\section{RESULTS AND DISCUSSION}

A dimensionless group that includes the dimensionless parameters in variables affecting the wave energy loss referred to as par1 (Eq. 10). The dimensionless wave energy loss (Eq. 11) is given below for a permeable beach:

$$
\begin{gathered}
\operatorname{par} 1=\frac{\mathrm{Ru} \cdot(\cot \beta)^{\mathrm{a}} \mathrm{G}_{\mathrm{sp}}}{\mathrm{r}^{\mathrm{b}} \cdot \mathrm{D}}, a=\frac{1}{\cot \beta}, \quad b=1.95 \\
\frac{\Delta \mathrm{E}}{\gamma_{\mathrm{w}} \mathrm{d}^{3}}=\left(\frac{\mathrm{E}_{\mathrm{i}}-\mathrm{E}_{\mathrm{r}}}{\gamma_{\mathrm{w}} \mathrm{d}^{3}}\right)
\end{gathered}
$$

The proposed relationship (Eq. 12) is obtained from Eq. 10, Eq. 11, Figure 5 and regression analysis. The correlation coefficient is calculated as 0.9 , referencing regression analysis.

$$
\left.\frac{\Delta \mathrm{E}}{\gamma_{\mathrm{w}} \mathrm{d}^{3}}=0.000008 \operatorname{par} 1\right)^{1.1013}
$$

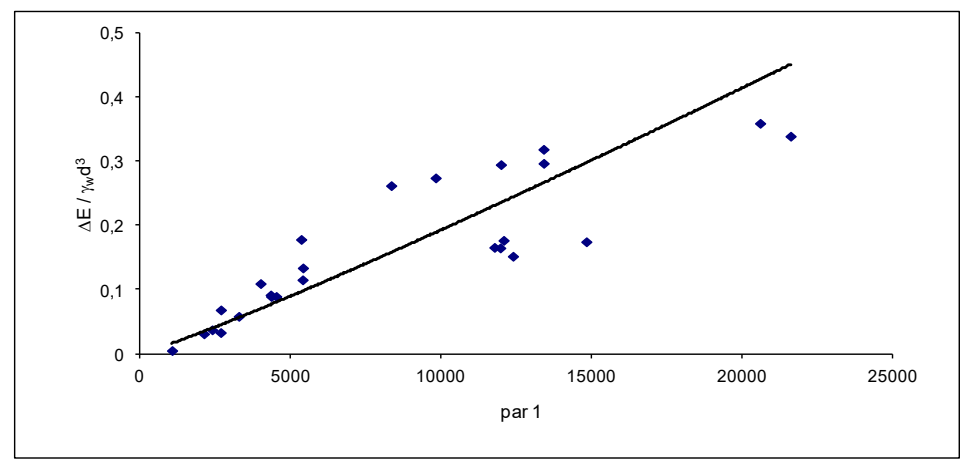

Figure 5. Variation of $\Delta \mathrm{E} / \gamma_{\mathrm{w}} \mathrm{d}^{3}$ versus par 1

To be able to verify the proposed equations, the experiments were repeated at a slope of $1 / 2.5,1 / 3.5$ and 1/6.5. The values for incident and reflecting wave heights defined in these experiments are substituted in Eq. 7, the total energy values of incident and reflecting waves were calculated. By using these values, the $\Delta \mathrm{E} / \gamma_{\mathrm{w}} \mathrm{d}^{3}$ was determined. The exchange of these values with $\Delta \mathrm{E} / \gamma_{\mathrm{w}} \mathrm{d}^{3}$ values obtained from the proposed equation (Eq. 12) is given in Figure 6 (a-b). It was observed that there was a good agreement between obtained $\Delta \mathrm{E} / \gamma_{\mathrm{w}} \mathrm{d}^{3}$ values from Eq. 7 and Eq. 12. The correlation coefficients are calculated as $0.93,0.97$ and 0.96 , respectively.

It can be seen from these figures that the wave energy loss is directly proportional to slope, incident wave height, and run-up height, while it is inversely proportional to reflection coefficient. 


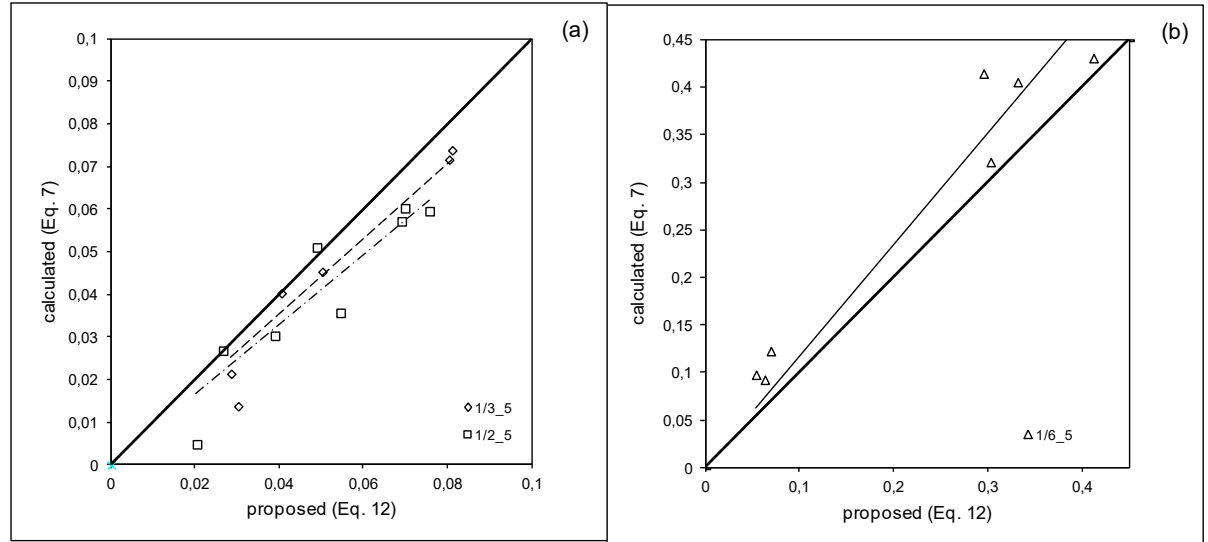

Figure 6. Comparison of tsunami energy loss calculated (Eq. 7) and proposed (Eq. 12) a) for 1/2.5 and $1 / 3.5$ beach slopes, $b$ ) for $1 / 6.5$ beach slope

\section{CONCLUSIONS}

In this study, the effects of the parameters reflection and energy loss of tsunami were analyzed experimentally. The beach was built as a natural sandy beach with grain diameter of $0.35 \mathrm{~mm}$ and specific gravity of 2.63. The experiments were performed on permeable beaches where the generated waves were nonbreaking during the run-up process.

According to the results derived from the study, the reflection coefficients decrease, while the dimensionless run-up height increases (Figure 2 and Table 1). Moreover, the reflection coefficient decreases as the incident wave height increases in each slope as shown in both Figure 3 and Table 2. When incident wave height increases, the run-up height increases as well. In the meanwhile, tsunami energy is consumed and thus, tsunami reflection decreases. Then, the parameters affecting reflection coefficient and energy loss of tsunami were determined. These parameters were not only written as a dimensionless group by using Buckingham's Pi theorem but also by considering regression analysis to give the relations regarding dimensionless wave energy loss (see Eq. 12). The values for incident and reflecting wave heights in these experiments were substituted in Eq. 7, and then the total energy values of incident and reflecting waves were calculated. These values were compared with the results of proposed equations, and there was found to be a balance within them. The research can be further advanced by taking the armoured, the regular and random placement of trees on slope beach, and different incident wave angles into consideration.

\section{REFERENCES}

[1] Liu PL - F, Synolakis CE, Yeh H H. Report on the International Workshop on long wave run-up. J Fluid Mech 1991; 229: 675-688.

[2] Synolakis CE. The runup of long waves. PhD, California Institute of Technology, 1986.

[3] Synolakis CE. The runup of solitary waves. J Fluid Mech 1987; 185: 523-545.

[4] Hall JV, Watts JW. Laboratory Investigation of The Vertical Rise of Solitary Waves on Impermeable Slopes. Tech. Memo. 33, Beach Erosion Board, Office of the Chief of Engineers, U.S. Army Corps of Engineers, 1953.

[5] Liu PL-F,Cho Y-S. An integral equation model for wave propagation with bottom frictions. J Waterw Port C-ASCE 1994; 120: 102-112. 
[6] Liu PL-F, Cho Y-S, Briggs MJ, Synolakis CE, Kanoglu U. Run-up of solitary wave on a circular island. J Fluid Mech 1995; 302: 259-285.

[7] Cho Y-S, Liu PL-F. Crest length effects in nearshore tsunami run-up around islands. J Geophys Res-Oceans; 1999: 104 (4), 7907-7913.

[8] Al-Banaa K, Liu P. Numerical study on the hydraulic performance of submerged porous breakwater under solitary wave attack. J Coastal Res Special Issue 2007; 50: 201 - 205.

[9] Li Y. Tsunamis: Non-Breaking and Breaking Solitary Wave Run-Up. Rep. KH-R-60, W. M. Keck Laboratory of Hydraulics and Water Resources, California Institute of Technology, Pasadena, CA, 2000.

[10] Silva R, Losada IJ, Losada MA. Reflection and transmission of tsunami waves by coastal structures. Appl Ocean Res 2000; 22: 215-223.

[11] Smith L, Jensen A, Pedersen G. Investigation of breaking and non-breaking solitary waves and measurements of swash zone dynamics on a $5^{\circ}$ beach. Coast Eng 2017; 120: 38-46.

[12] Wang Q, Guo X, Wang B, Liu H. Experimental measurements of solitary wave attenuation over shallow and intermediate submerged canopy. China Ocean Eng 2016; 3: 375-392.

[13] Wu YT, Hsiao SC. Propagation of solitary waves over a submerged permeable breakwater. Coast Eng 2013; 81: 1-18.

[14] Mo W, Jensen A, Liu PL-F. Plunging solitary wave and its interaction with a slender cylinder on a sloping beach. Ocean Eng 2013; 74: 48-60.

[15] Tadepalli S, Synolakis CE. The run-up of N-waves on sloping beaches. P Roy Soc Lond A Mat 1994; 445: 99-112.

[16] Tadepalli S, Synolakis CE. Model for the leading waves of tsunamis. Phys Rev Lett 1996; 77 : $2141-2145$.

[17] Cooker MJ, Weidman PD, Bale, DS. Reflection of a high amplitude solitary wave at a vertical wall. J Fluid Mech 1997; 342: 141-158.

[18] Chen C-Y., Hsu JR-C, Cheng M-H, Chen H-H, Kuo C-F. An investigation on internal solitary waves in a two-layer fluid: propagation and reflection from steep slopes. Ocean Eng 2007; 34: 171184.

[19] Chang HK, Liou JC. Long wave reflection from submerged trapezoidal breakwaters. Ocean Eng 2007; 34: 185-191.

[20] Kajiura K. Tsunami source, energy and the directivity of wave radiation, B Earthq Res I Tokyo 1970; 48: 835-869.

[21] Dotsenko SF, Korobkova TY. The effect of frequency dispersion on plane waves generated as a result of bed motions. Phys Oceanogr 1997; 8 (3): 143-154.

[22] Velichko AS, Dotsenko SF, Potetyunko, E’N. Amplitude-energy characteristics of tsunami waves for various types of seismic sources generating them. Phys Oceanogr 2002; 12: 308-322. 
[23] Li Y, Raichlen F. Non-breaking and breaking solitary wave run-up. J Fluid Mech 2002; 456: 295318.

[24] Okal EA. Normal mode energetics for far-field tsunamis generated by dislocations and landslides. Pure Appl Geophys 2003; 160: 2189-2221.

[25] Okal EA, Synolakis CE. A theoretical comparisons of tsunamis from dislocations and landslides. Pure Appl Geophys 2003; 160: pp. 2177-2188.

[26] Dutykh D, Dias F. Energy of tsunami generated by bottom motion. P Roy Soc Lond A Mat 2009; 465: 725-744.

[27] Kathiresan K, Rajendran N.Coastal mangrove forests mitigated tsunami. Estuar Coast Shelf S 2005; 65: 601-606.

[28] Harada K, Imamura F. Effects of coastal forest on tsunami hazard mitigation - A preliminary investigation. In: Satake, K., editors. Tsunamis, Case Studies and Recent Developments, Springer, Netherlands, 2005. pp. 279-292.

[29] Edward JKP, Terazaki M, Yamaguchi M. The impact of tsunami in coastal areas: Coastal protection and disaster prevention measures-experiences from Japanese Coasts. Coast Mar Sci 2006; 30: 414-424.

[30] Dahdouh-Guebas, F. Mangrove Forests and Tsunami Protection. New York, USA: McGraw-Hill Professional, 2006.

[31] Latief $\mathrm{H}$, Hadi S. The role of forests and trees in protecting coastal areas against tsunamis. In: 2007 Proceedings of the Regional Technical Workshop, Khao Lak, Thailand, 28-31 August 2006, pp. $5-24$.

[32] Yanagisawa H, Koshimura S, Goto K, Miyagi T, Imamura F, Ruangrassamee A, Tanavud, C. The reduction effects of mangrove forest on a tsunami based on field surveys at Pakarang Cape, Thailand and numerical analysis. Estuar Coast Shelf S 2009; 81: 27-37.

[33] Irtem E, Gedik N, Kabdasli MS, Yasa NE. Coastal forest effects on tsunami run-up heights. Ocean Eng 2009; 36: 313-320.

[34] Irtem E, Kabdasli MS, Gedik N. Coastal protection measures for tsunami disaster reduction. In: Veitch, N. and Jaffray, G. editors. Tsunamis: Causes, Characteristics, Warnings and Protection, Nova Science Publishers, Inc., New York, 2010. pp. 113-129.

[35] Grilli ST, Svendsen IA, Subramanya R. Breaking criterion and characteristics for solitary waves on slopes. J Waterw Port C-ASCE 1997; 123: 102-112.

[36] CEM, (2003). Coastal Engineering Manual. Coastal Engineering Research Center, Department of Army Corps of Engineers, US, Chapter I, Part 2.

[37] Gedik N, Irtem E, Kabdasli S. Laboratory investigation on tsunami run-up. Ocean Eng 2005; 32: 513-528.

[38] Gedik N, Irtem E, Kabdasli S. Experimental investigation on solitary wave run-down and its effects on armor units. Coast Eng J 2006; 48: 337-353. 